\title{
Reliability Analysis of Expansive Soil Slope Stability Based on the Three-Broken Line Model
}

\author{
Wenwei Li $\mathbb{D}^{1,2}$ Baotian Wang, ${ }^{1,2,3}$ Jinyu Zuo, ${ }^{1,2}$ Bingsheng Zhou, ${ }^{1,2}$ and Haixia Zhang ${ }^{1,2}$ \\ ${ }^{1}$ Key Laboratory of Ministry of Education for Geomechanics and Embankment Engineering, \\ College of Civil and Transportation Engineering, Hohai University, Nanjing, China \\ ${ }^{2}$ Jiangsu Research Center for Geotechnical Engineering Technology, College of Civil and Transportation Engineering, \\ Hohai University, Nanjing, China \\ ${ }^{3}$ Department of Water Conservancy and Civil Engineering, Tibet Agricultural and Animal Husbandry University, Linzhi, China
}

Correspondence should be addressed to Wenwei Li; 848640016@qq.com

Received 7 December 2020; Revised 20 January 2021; Accepted 17 March 2021; Published 1 April 2021

Academic Editor: Xinyu Xie

Copyright (c) 2021 Wenwei Li et al. This is an open access article distributed under the Creative Commons Attribution License, which permits unrestricted use, distribution, and reproduction in any medium, provided the original work is properly cited.

Based on the characteristics of an expansive soil slope, the slip mass can be simplified to a simpler model with three-broken line rigid bodies. A solution was formulated to calculate the safety factors of the slope, and the results are similar to those based on the strength reduction method. However, similar to conventional methods to analyze the stability of slopes, the deterministic method to obtain the safety factors only calculates the safety factor using deterministic values without considering the randomness of soil parameters, which leads to unstable results. To improve the rationality of the calculated results, this paper aims to construct a reliability analysis method based on the simplified three-broken line model of a landslide. The reliability is calculated with the response surface method in a spreadsheet with efficiency and convenience. The designed program considers the changes in the strength of the shallow soil and the depth of the strongly weathered layer for different stages of the wetting-drying cycles and solves for the probability of failure of the sliding surface at the interface between the strong and weak weathered layers. Considering an expansive soil slope as an example, the reliability of the slope was analyzed based on laboratory test data and the proposed formula. The results show that multiple wetting-drying cycles significantly increase the probability of failure of an expansive soil slope and that the slope typically becomes unstable after six wetting-drying cycles. Slope cutting helps alleviate the adverse effects of wettingdrying cycles.

\section{Introduction}

Expansive soils are typical of problematic soils $[1,2]$ - a kind of high-plastic clay with an expansive structure, multifissures, strong expansion, and contraction, as well as strength attenuation. They can be widely discovered all over the world [3], which may easily cause engineering problems $[4,5]$. In the area of the expansive soil, expansive soil landslide is one of the most common and special slope deformation phenomena $[6,7]$, which is also viewed as one of the most important engineering geological problems in this field [8].

Over the past decades, many scholars have studied the stability evaluation of the expansive soil slope. Wang et al. [9] made a local physical model to assess the stability evaluation of the expansive soil slope in the An Kang area. Xie et al. [10] developed a stability analysis method based on the upper bound theory of limit analysis to consider the crack effect for the expansive soil slope. Based on the fuzzy recognition theory and the analytic hierarchy process (AHP), Jian et al. [11] worked out a recognition model to evaluate the stability of expansive soil slopes. Qi and Vanapalli [12] considered the influence of swelling behavior in the stability of the unsaturated expansive soil slope and addressed the shallow expansive soil slope failure mechanism. Wen et al. [13] managed to apply a multistage fuzzy comprehensive evaluation model to an unloading high-steep slope, whose stability analysis shows great feasibility. Based on the fish and Gaussian process regression (GPR) model, Peng et al. [14] proposed a numerical model and applied it to 
dynamic predictions of shallow sliding failures of expansive soil slopes. However, most of the research is conducted on numerical simulation, which usually takes users' time to set up relevant models. In engineering practice, it is most convenient to obtain the safety factors by using relevant formulas. To date, there are still some deficiencies in the analytical formula of safety factors, which can reflect the stability of expansive soil slopes.

On the contrary, deterministic methods to obtain the safety factors are unlikely to quantify the influence of the uncertainties embedded in soil parameters. Therefore, great efforts have been put into the reliability analysis-which outperforms conventional deterministic methods-of soil slope stability. Li et al. [15] made use of a simple limit equilibrium method (LEM) and the finite element method (FEM) to evaluate the failure probability of slope stability. Cao et al. [16] applied an advanced MCS method called "subset simulation" to slope stability problems in a spreadsheet. Zhang et al. [17] proposed a new method for the system reliability analysis of soil slopes, which is helpful to calculate the system failure probability based on certain typical slip surfaces, which are of great importance to the system reliability analysis. Johari and Gholampour [18] used the conditional random finite element method to predict the unsaturated soil behavior and estimate suctions in a finite element analysis.

In this paper, a reliability-based stability evaluation method is proposed aimed at the expansive soil slope of the three-broken line model, which is based on the instability mechanism and sliding body geometry. The reliability is calculated with the response surface method. To ease its application in engineering practice, the whole procedure is encoded in a spreadsheet, and the reliability analysis is carried out on the basis of this method.

\section{Limit Equilibrium Method}

2.1. Triple-Line Rigid-Body Model. Data from several field studies [19-21] indicate that the sliding surface of an expansive soil slope shows the following characteristics after losing stability: (1) the dangerous sliding surface is located at the interface between the strong and weak weathered layers, and there is consistency in the sliding surface, crack, and atmospheric impact depths. (2) The sliding surface is dependent on the long fracture surface. (3) The rear edge of the landslide is usually a vertical tension fissure, and in general, the main sliding bed in the lower portion of the landslide is almost horizontal. Based on the characteristics of the expansive soil, the back edge (fissure) is considered to be the depth of the tension crack without strength, and water pressure on the soil is due to rainfall. When the angle of the slope is relatively large, the strength of the soil at the middle (i.e., the sliding surface) can be determined from the strength of multiple wetting-drying cycles (the cycle times may differ for different kinds of soil slopes with different angles). When the angle of the slope is relatively small, the strength of the soil with filling fissures can be considered to be representative of the strength of the soil.
According to this, a three-broken rigid-body model is proposed to reflect the effects of fissures and wetting-drying cycles, as shown in Figure 1.

The geometric model of the slip mass is shown in Figure 2. According to the basic size of the figure, the area of the slip mass can be calculated as

$$
S=S_{\mathrm{ABCD}}-S_{\mathrm{CEF}}=\frac{1}{2}\left(h_{1}+h_{2}\right)\left(\frac{2 h_{1}}{\sin \theta}+\frac{h_{2}-h_{1}}{\tan \theta}\right)-\frac{\mathrm{h}_{2}^{2}}{2 \tan \theta},
$$

where $S$ is the area of the slip mass, $h_{1}$ is the thickness of the strong weathering layer, $h_{2}$ is the thickness of the expansive soil layer below the strongly weathered layer, and $\theta$ is the slope angle.

The self-weight of the slip mass is

$$
W=p g S=p g\left[\frac{1}{2}\left(h_{1}+h_{2}\right)\left(\frac{2 h_{1}}{\sin \theta}+\frac{h_{2}-h_{1}}{\tan \theta}\right)-\frac{h_{2}^{2}}{2 \tan \theta}\right],
$$

where $W$ is the weight of the slip mass, $p$ is the equivalent density of the slip mass, and $g$ is a constant of gravitational acceleration.

The dangerous slip surface can be simplified as a folded slip surface consisting of three straight lines. The upper part of the fold line is a vertical crack formed due to weathering. The tension crack surface does not bear the force of the stable slope. The depth of the vertical crack refers to the depth of the strong weathering layers. The broken line in the middle is straight and coincides with the interface of the strong and weak weathering layers and is parallel to the slope surface. The bottom shear surface is simplified into a horizontal straight line. The thickness of the strong weathering layer is set as $h_{1}$, the thickness of the expansive soil layer below the strong weathering layer is set as $h_{2}$, and the strength index of the expansive soil after eight wetting-drying cycles is adopted to represent the adverse effects of wetting-drying cycles of the slope soil. If the sliding body reaches the limit of the equilibrium state of critical instability and the adverse effects of crack water pressure at the top of the slope are considered, then the entire sliding body can be regarded as a rigid body that bears force. The analysis is shown in Figure 3.

Based on the static equilibrium of the sliding body, the equation is established in the horizontal and vertical rectangular coordinate system:

$$
\begin{aligned}
& \sum F_{y i}=0 N_{1} \cos \theta+N_{2}+T_{1} \sin \theta-W=0, \\
& \sum F_{x i}=0 T_{1} \cos \theta+T_{2}-N_{1} \sin \theta-P=0,
\end{aligned}
$$

in which

$$
\begin{aligned}
& T_{1}=\frac{c+\sigma_{1} \tan \phi}{F_{s}} \times \frac{h_{2}}{\sin \theta}, \\
& T_{2}=\frac{c+\sigma_{2} \tan \phi}{F_{s}} \times \frac{h_{1}}{\sin \theta},
\end{aligned}
$$




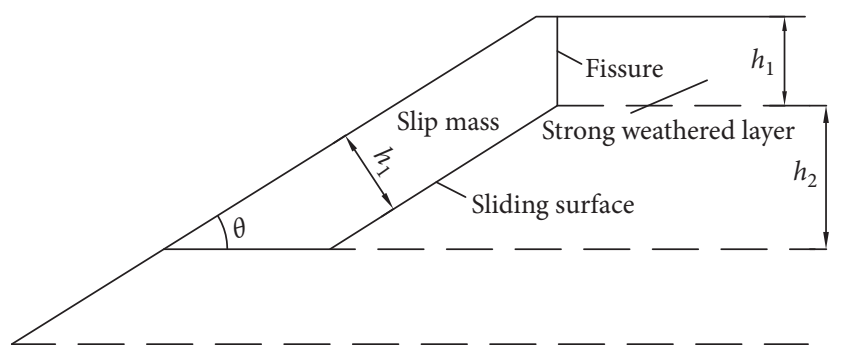

FIgURE 1: Schematic diagram of the global rigid body model.

$$
\begin{aligned}
& N_{1}=\sigma_{1} \times \frac{h_{2}}{\sin \theta}, \\
& N_{2}=\sigma_{2} \times \frac{h_{1}}{\sin \theta}, \\
& P=\frac{1}{2} p_{w} g h_{1}^{2}, \\
& \sigma_{1}=p g h_{1} .
\end{aligned}
$$

$T_{1}, N_{1}$, and $\sigma_{1}$, respectively, refer to the antisliding force, normal pressure, and normal stress on the slip surface of the middle broken line segment; $T_{2}, N_{2}$, and $\sigma_{2}$, respectively, refer to the antisliding force, normal pressure, and normal stress on the slip surface of the lower broken line segment; $P$ is the pore water pressure in the crest of the slope; $p_{w}$ is the density of fracture water.

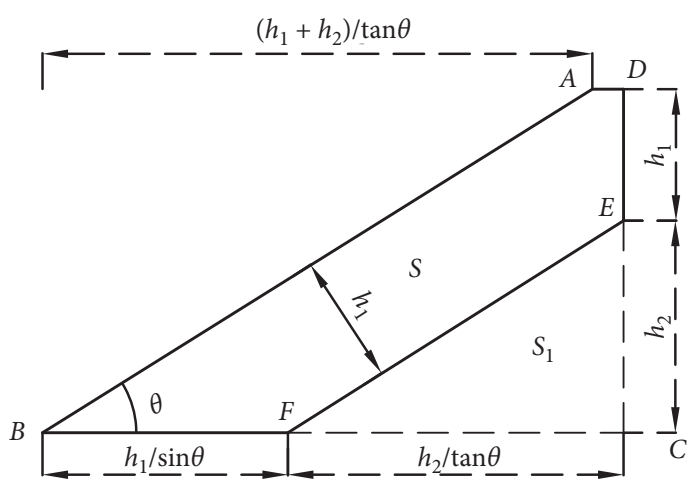

Figure 2: Schematic diagram of the geometric model.

Through the solution of the equation, the following conclusions can be reached:

$$
a F_{s}^{2}+b F_{s}+c=0 .
$$

$F_{S}$ is the safety factor of the slope, in which

$$
\begin{aligned}
& a=\frac{p g h_{1} h_{2}}{\tan \varphi} \\
& b=-W-\frac{c h_{1}}{\sin \theta \cdot \tan \varphi}-\frac{c h_{2}}{\tan \theta \cdot \tan \varphi}, \\
& c=c h_{2}+p g h_{1} h_{2} \tan \varphi
\end{aligned}
$$

The solution of the original equation is

$$
F_{s}=\frac{W+\left(c h_{1} / \sin \theta \cdot \tan \phi\right)+\left(c h_{2} / \tan \theta \cdot \tan \phi\right)+\sqrt{\left(W+\left(c h_{1} / \sin \theta \cdot \tan \phi\right)+\left(c h_{2} / \tan \theta \cdot \tan \phi\right)\right)^{2}-\left(4 \rho g h_{1} h_{2}+2 p_{w} g h_{1}^{2} / \tan \phi\right)\left(c h_{2}+\rho g h_{1} h_{2} \tan \phi\right)}}{\left(2 \rho g h_{1} h_{2}+p_{w} g h_{1}^{2} / \tan \phi\right)} .
$$

2.2. Discussion on Applicability. Yin and Bin [22] proposed a method that represents the effect of the fissure on the slope and divides the fissure area of an expansive soil slope based on the region and strength. To verify the accuracy of the model proposed in this paper, FLAC was applied based on the method proposed by Yin and Bin to evaluate the stability of a slope selected near the Qinhuai River in Nanjing, Jiangsu Province, China, and the results were compared with the results obtained with the integral rigid body equilibrium method. The width of the landslide body was about $80 \mathrm{~m}$; the length of the main axis was about $30 \mathrm{~m}$; the width of the back edge crack was $0.3-1.0 \mathrm{~m}$; the depth was $2.0 \mathrm{~m}$; and the height of the back edge wall was $1.0 \mathrm{~m}$. Based on these dimensions, the thickness of the fully developed fracture layer was $2 \mathrm{~m}$, and that of the underdeveloped layer was $1 \mathrm{~m}$. The typical geological sections of the excavation section were, respectively, $1: 2,1: 2.5,1: 3,1: 3.5$, and $1: 4$ for a comparative analysis. The basic shape of the slope is shown in Figure 4.

The typical slope shown in Figure 4 was used to build models with different slope ratios and was used in FLAC3D software. The boundary conditions were selected to impose horizontal constraints on the model boundary. The bottom boundary was fixed, that is, the bottom boundary was vertical with zero horizontal displacement; the top of the slope was a free boundary. At the bottom of the model, the portions of the slope with fewer effects were divided into wider meshes, and the upper part of the model was divided into denser meshes. A total of 840 meshes and 2640 nodes were created. The rock and soil body adopted an M-C constitutive model, and its parameters were obtained from laboratory tests and are listed in Table 1 . In the three-broken rigid-body model, $h_{1}=2 \mathrm{~m}, h_{2}=8 \mathrm{~m}$, and $\varphi=11.8^{\circ}$. Five different slope ratios were selected for comparison, and the contrast results of FS are shown in Figures 5 and 6.

As shown in Figure 6, the safety factor calculated using the integral rigid body equilibrium method does not show much of a difference from that calculated with the FLAC strength reduction method, although the former is slightly smaller than the latter. The main reason for this is that the effect of fracture depth was considered in the three-fold line model of the integral rigid body equilibrium method, while 


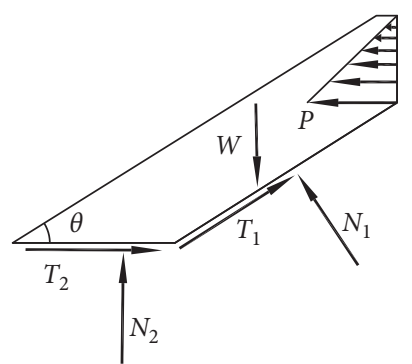

(a)

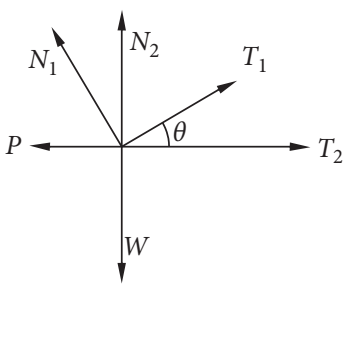

(b)

FIGURE 3: Force diagram of the slip mass.

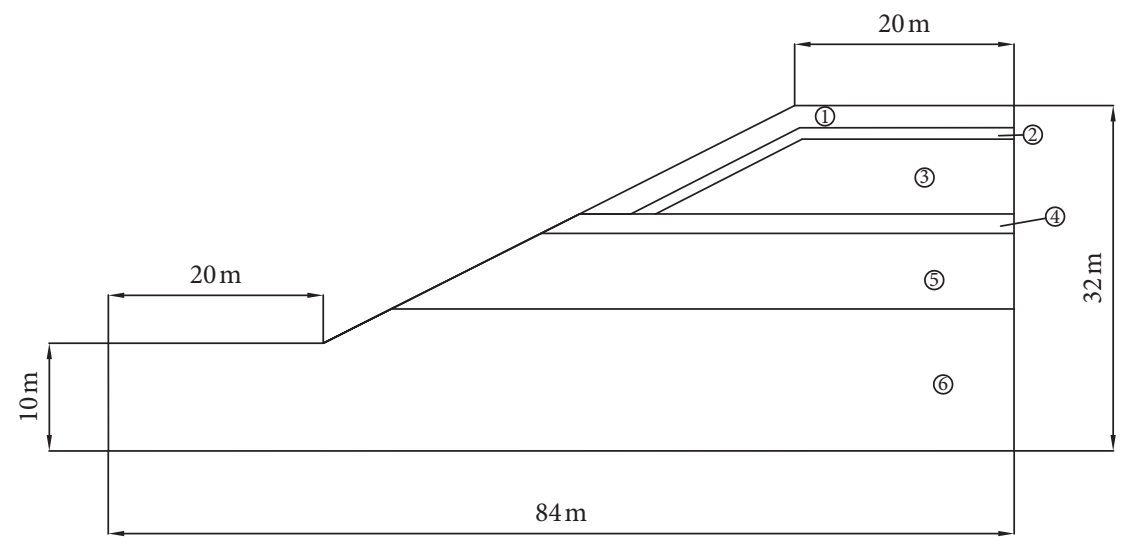

FIGURE 4: Basic shape of the expansive soil slope.

TABLE 1: Values employed in the stability analysis of an expansive soil slope.

\begin{tabular}{lccccc}
\hline Soil layer & Cohesion $(\mathrm{kPa})$ & Friction angle $\left(^{\circ}\right)$ & Unit weight $\left(\mathrm{kN} \cdot \mathrm{m}^{3}\right)$ & Modulus of elasticity $(\mathrm{MPa})$ & Poisson's ratio \\
\hline 1 & 3.2 & 11.8 & 20.11 & 5.13 & 5.13 \\
2 & 17.95 & 12.75 & 20.11 & 5.13 & 0.27 \\
3 & 33.5 & 13.6 & 20.11 & 9650 & 0.27 \\
4 & 2.0 & 48.65 & 25.65 & 9650 & 0.27 \\
5 & 3.0 & 48.65 & 25.65 & 12,400 & 0.275 \\
6 & 5.3 & 48.65 & 25.65 & & 0.275 \\
\hline
\end{tabular}

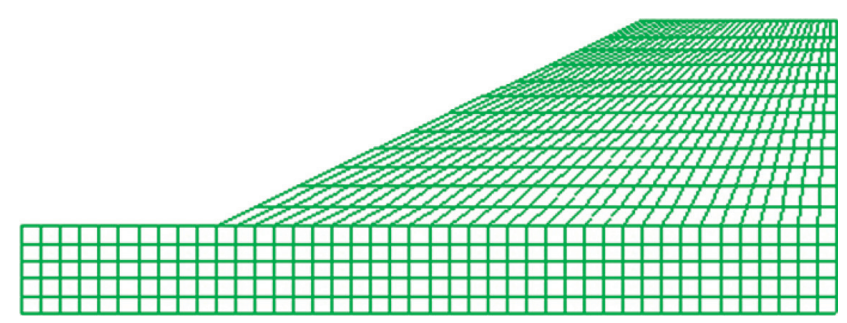

(a)

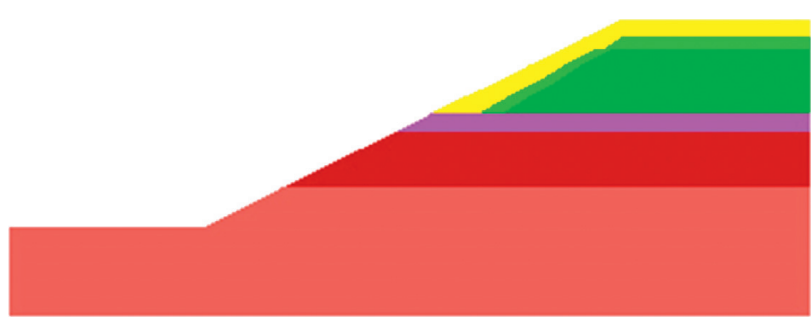

(b)

Figure 5: The model established in FLAC3D. (a) Meshes in the model. (b) The basic situation of the model. 


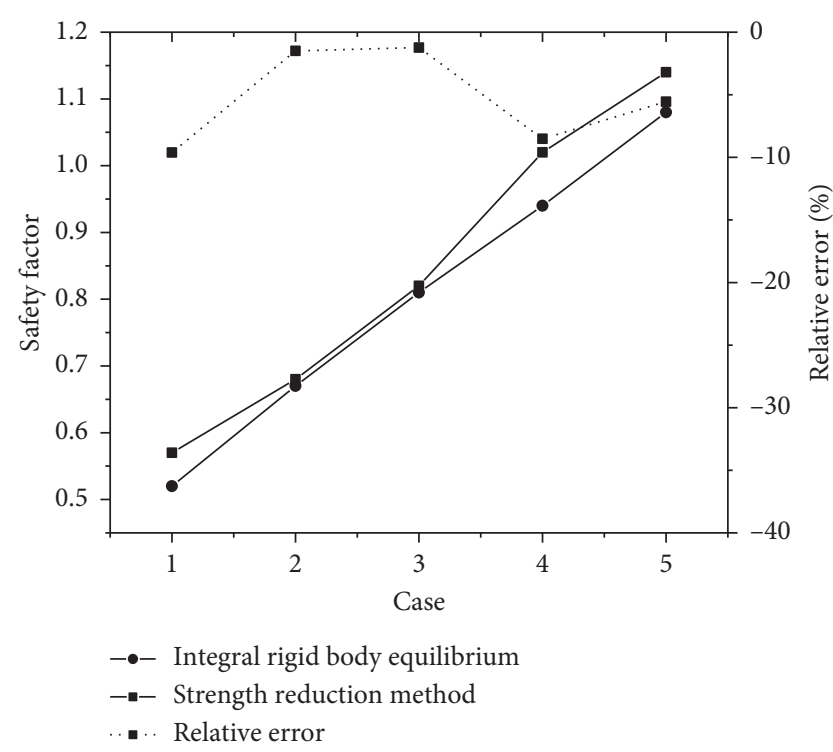

FIGURE 6: Comparison of the integral rigid body equilibrium and strength reduction method.

the fracture surface bears no force. However, the strength reduction method in FLAC only considers the strength of composite soil with fissures, which does not reflect the detrimental effects of crack development on the slip mass. Therefore, the integral rigid body equilibrium method proposed in this paper better reflects the actual situation of the expansive soil slope. Furthermore, it must be noted that the proposed three-fold rigid-body model is not fixed and unique. Instead, it can be generalized and modified according to specific engineering conditions and can be adapted to more complex expansive soil slopes. Therefore, establishing the static equilibrium of the integral sliding body can be considered as one of the reference methods to obtain the safety factors of slopes in future studies.

\section{Response Surface Method}

It has been well established that the Monte Carlo method is the most accurate method for calculating reliability [23], but is not very efficient $[24,25]$. Consequently, this method is not suitable for being adopted in an Excel spreadsheet which is designed to simplify the application of the calculation of reliability in engineering practice. It has been demonstrated in several studies that the central-point method has the advantages of simplicity and rapidity but has low accuracy. Thus, to achieve a quick calculation with sufficient accuracy, the response surface method (RSM) is adopted in the calculation of reliability. To better improve the fit of the limit state function, the reliability should be solved by iterating the response surface method. Low et al. [26-28] utilized the spreadsheet method to calculate the reliability using the "SOLVER" programming solution of the spreadsheet with corresponding programming. However, it is time-consuming to call the "SOLVER" routine for each reliability calculation. If multiple calls are needed for the entire iterative process, then the calculation time increases. Also, due to the nonlinearity of the limit state function, if the initial value is not appropriate, then the spreadsheet method with "SOLVER" is easily disrupted, and no solution is obtained.

Therefore, to save computing time and computational collapse due to repeated calls of "SOLVER" during the iterative process, this paper presents the calculation of reliability based on the RSM without using "SOLVER" in the spreadsheet, using Visual Basic for Applications (VBA) programming and other built-in functions.

3.1. Limit State Function. According to the three-broken line mode proposed in this paper, the limit state function (LSF) can be expressed as

$$
Z=F S-1=F_{s}=\frac{W+\left(c h_{1} / \sin \theta \cdot \tan \phi\right)+\left(c h_{2} / \tan \theta \cdot \tan \phi\right)-\sqrt{\left(W+\left(c h_{1} / \sin \theta \cdot \tan \phi\right)+\left(c h_{2} / \tan \theta \cdot \tan \phi\right)\right)^{2}-4\left(\rho g h_{1} h_{2} / \tan \phi\right)\left(c h_{2}+\rho g h_{1} h_{2} \tan \phi\right)}}{\left(2 \rho g h_{1} h_{2} / \tan \phi\right)}-1 .
$$

3.2. Random Variables. The reliability calculation of the slope has been explored by many scholars. Based on the existing research, it can be found that the internal friction angle of the soil and the cohesive force are usually regarded as random variables in the reliability analysis of slopes, while other parameters are usually viewed as deterministic variables [29-32]. Two distribution types, namely, normal distribution and lognormal distribution, are taken into account for the random variables in this study.

3.3. Iterative Response Surface Method. The RSM aims to construct a closed-form polynomial function [30], which is approximately equal to the actual limit state function in the region with the maximum contribution to the probability of failure. Reliability analysis can then be easily performed on this response surface. To evaluate the reliability index based on the proposed model, an iterative RSM is used for this study. The quadratic polynomial function without crossterms is defined as

$$
Z=a_{0}+\sum_{i=1}^{n} b_{i} x_{i}+\sum_{i=1}^{n} c_{i} x_{i}^{2},
$$

where $a_{0}, b_{i}$, and $c_{i}$ are coefficients to be determined and $n$ is the number of random variables. Using the RSM, one can easily obtain the reliability index, $\beta$, and the design point, $u^{*}$. The response surface function assumed in this paper is 


$$
Z=a_{0}+b_{1} c+b_{2} c^{2}+c_{1} \tan \varphi+c_{2}(\tan \varphi)^{2} .
$$

The specific process of calculating reliability by the iterative response surface method is summarized in Figures 2 and 7.

3.4. Discussion on Applicability. To verify the applicability of the RSM to the model proposed in this paper, based on the relevant parameters of the expansive slope near the Qinhuai River in Nanjing, Jiangsu Province, China, $h_{1}=2 \mathrm{~m}$, $h_{2}=8 \mathrm{~m}$, and slope ratio is $1: 4$. The basic parameters of the undisturbed soil at the depth of $5.5 \mathrm{~m}$ in a section of the expansive slope were obtained from laboratory tests (after eight wetting-drying cycles), as shown in Table 2. According to the results of 30 sets of rapid shear tests, the discreteness of the data was not large; hence, the coefficient of variation of the parameters is 0.1 .

After 5 iterations, the response surface function obtained by fitting is

$$
\begin{aligned}
Z= & -1.001+0.120 c-0.0000439 c^{2}+4.172 \tan \varphi \\
& -0.014(\tan \varphi)^{2} .
\end{aligned}
$$

A thousand cases of different combinations generated by the Monte Carlo method for $c$ and $\varphi$ are used herein to verify the fitting effect. According to the results of the calculations, the coefficient of determination $R^{2}$ was found to be 0.975 , which indicates that the response surface function obtained by fitting was very close to the actual function.

3.5. Response Surface Method in a Spreadsheet. Although the Monte Carlo method is currently viewed as the most accurate method to calculate reliability, additional mathematical calculation software such as MATLAB is necessary [24], as a result of which the calculation efficiency is greatly affected by the number of samples. To make the calculations dependable, simple, and user-friendly, Excel software is used for the calculation of reliability [26]. With the aid of VBA in Excel and its built-in function library, the RSM can be realized in a spreadsheet to calculate reliability. Although Excel software does not have an inherent quadratic fitting function, it can assume that the quadratic term is a random variable, obtain the response surface function with the help of the built-in function "Linest," and calculate reliability by VBA programming without the aid of "SOLVER," which avoids frequent calls to "SOLVER" in the iterative process, and hence, calculation crashes due to parameter problems.

To verify the accuracy of the iterative RSM in the spreadsheet, reliability results with 1,000,000 Monte Carlo simulations were considered as reference. The results and time comparisons between the proposed method in the spreadsheet and some other methods are shown in Table 3.

The results show that, for both types of random variable distributions, the RSM provides a good approximation of MCS, with the absolute relative error less than $1 \%$, and the calculation time is only $1 / 200$ of MCS, which proves that the iterative RSM can be used as an alternative for calculating reliability using the whole rigid body equilibrium method. It is worth noting that when using "SOLVER" to calculate reliability, the process collapses several times due to inappropriate initial values being selected which results in no solution, and the goal of the current study is to avoid this scenario while using the RSM.

The spreadsheet method [26-28] can obtain values of reliability close to those of the MCS for a normal distribution, and the calculation time is less than $0.5 \mathrm{~s}$; when the distribution type is lognormal, the calculation time is significantly increased due to the need for equivalent normalization. Additionally, the deviation from the MCS is higher than that of the normal distribution. A single calculation is very time-consuming. When the method is used iteratively, the calculation time is more than 100 times that of the method proposed in this paper, which reiterates that the method in this paper is more efficient. Therefore, the RSM in the spreadsheet can be used for its efficiency and accuracy.

Based on the limit state function of the expansive soil slope proposed in this paper, the entire procedure was encoded in a spreadsheet as shown in Figure 8, which further increases the ease of application of the proposed method in engineering practice. Thus, users can input the corresponding mean and coefficient of variation based on the values of soil parameters obtained from experiments. To avoid the number of user experimental samples from being too small, the coefficient of variation can also be chosen according to the three levels built in the table, i.e., low, medium, and high [33].

\section{Reliability Analysis}

4.1. Effect of Wetting-Drying Cycles on Slope Stability Reliability. Expansion due to water absorption and shrinkage due to water loss are the main reasons why expansive soil cannot be used as a roadbed filler. In engineering practice, repeated expansion and contraction of the expansive soil results in cracks in the soil, loosens the structure, and causes parts of the deformation to be irrecoverable. For indoor tests, to better simulate crack development and soil deformation caused by wetting-drying cycles of the soil, rapid wetting-drying cycles are applied to simulate the on-site situation. In the experiment, a prepared ring knife sample (as shown in Figure 9) was placed on a permeable stone, and capillary water was used to humidify the soil to the moisture content of the soil in the rainy season and thereafter naturally air-dried to the lowest moisture content of the soil in the dry season. The moisture content change path of the wetting-drying cycles used in this test is shown in Figure 10. The sample was weighed every 2 hours as shown in Figure 9(b) to ensure that the moisture content of the sample met the moisture content change path. As shown in Figure 11, cracks were detected after drying during the test.

After each wetting-drying cycle, the soil samples were air-saturated and subsequently subjected to a direct shear test to measure their consolidated fast shear strength. According to the strength obtained from the direct shear test, the strength index of the soil sample was calculated, and 


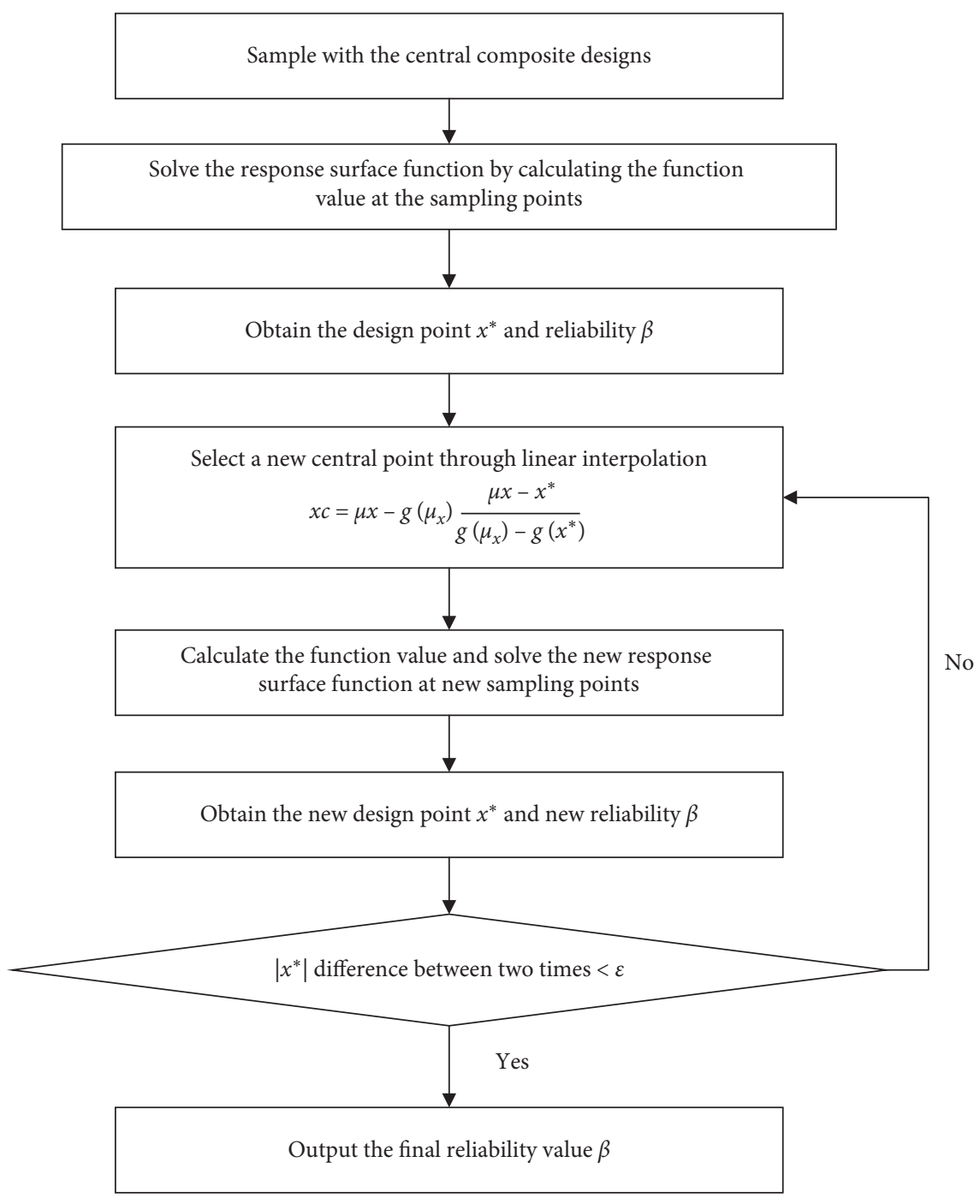

FIGURE 7: The calculation flowchart of the response surface method.

TABLE 2: Basic soil property.

\begin{tabular}{lccc}
\hline$c(\mathrm{kPa})$ & $\varphi\left({ }^{\circ}\right)$ & Density $\left(\mathrm{g} / \mathrm{cm}^{3}\right)$ & Water content $(\%)$ \\
\hline 3.2 & 11.8 & 1.99 & 22.9 \\
\hline
\end{tabular}

the relationship between cohesion, internal friction angle, and the number of wetting-drying cycles was obtained as shown in Figures 12 and 13.

It can be seen from the figures that due to the action of the wetting-drying cycle, the cohesion of the expansive soil was attenuated, with the attenuation being an exponential function. The internal friction angle showed fluctuations, but the deviations were not large. The wetting-drying cycles resulted in a substantial impact on the cohesion of the expansive soil.

In an analysis of wetting-drying cycles on the stability of an expansive soil slope, the following two points should be considered: one is the gradual attenuation of the strength of shallow soil and the other is the gradual deepening of the weathering layer due to the wetting-drying cycle.
The numerical value of the strength of the shallow soil of the slope at each stage of a wetting-drying cycle is presented in the above test results, and the development of the weathering layer depth is determined by assuming the relationship between the soil strength and the weathering layer depth.

During wetting-drying cycles, soil cracks develop gradually, and soil strength attenuates correspondingly. Assuming that the expansive soil undergoes the entire attenuation process after eight wetting-drying cycles, the absolute value of the soil strength attenuation after $i$ wettingdrying cycles is $\Delta c_{i}$, and if the strength attenuation completion degree $n_{i}$ is defined, then $n_{i}=\left(\Delta c_{i} / \Delta c_{8}\right)$, and then the corresponding relationship between wetting-drying cycle times and strength attenuation completion degree can be shown as in Figure 14.

The essential reason for the decline in soil strength lies in the development of cracks in the soil, and the degree of development of cracks in the soil also corresponds to the increase in thickness of the strong weathering layer. Assuming that the expansive soil completes the entire process 
TABLE 3: Comparison results of different reliability calculation methods.

\begin{tabular}{lcccccc}
\hline \multirow{2}{*}{ Method } & \multicolumn{2}{c}{ Reliability } & \multicolumn{2}{c}{ Deviation from MCS (\%) } & \multicolumn{2}{c}{ Time (s) } \\
& Normal & Lognormal & Normal & Lognormal & Normal & Lognormal \\
\hline MCS & 2.69 & 2.98 & - & - & 38.7 & 157.4 \\
Spreadsheet method & 2.67 & 3.04 & 0.7 & 2 & 0.2 & 1.1 \\
RSM (with "SOLVER") & 2.67 & 2.95 & 0.7 & 1.0 & 2.3 & 18.1 \\
This paper & 2.67 & 2.96 & 0.7 & 0.6 & 0.02 & 0.04 \\
\hline
\end{tabular}

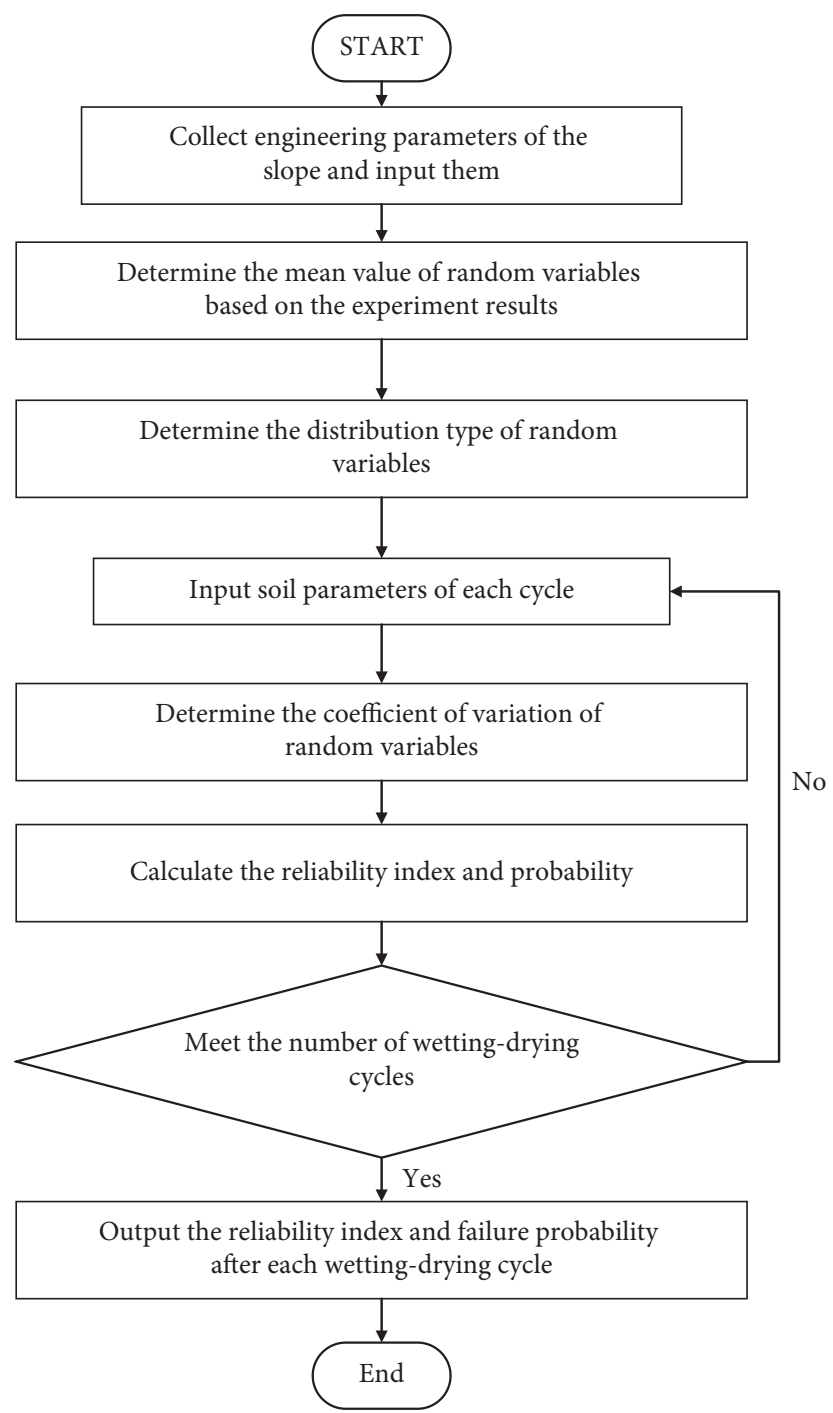

FIGURE 8: Reliability-based stability analysis of an expansive soil slope in a spreadsheet.

of increasing the thickness of the strongly weathered layer after eight wetting-drying cycles, the degree of development $\delta_{i}$ of the strongly weathered layer is defined as the ratio of the strongly weathered layer thickness $h_{1 i}$ to the final weathered layer thickness $h_{1}$ after $i$ wetting-drying cycles, i.e., $\delta_{i}=\left(h_{1 i} / h_{1}\right)$. In this paper, the relationship between the depth of the strongly weathered layer and the number of wetting-drying cycles is obtained using $\delta_{i}=n_{i}$, which is shown in Figure 15.

The probability of failure of the interface between the strong and weak weathering layers at different stages of the wetting-drying cycles can be predicted based on the reliability calculated per the above assumption, and the relationship between the probability of failure and the number of wetting-drying cycles is presented in Figure 16.

As shown in Figure 16, when the slope ratio is lower than $1: 3$, the probability of failure increases significantly after 6 or 7 wetting-drying cycles, which indicates that the model proposed in this paper, when combined with probability methods, can better reflect the adverse effects of wettingdrying cycles that affect the stability of the expansive soil slope. When the slope ratio increases, the stage at which the 


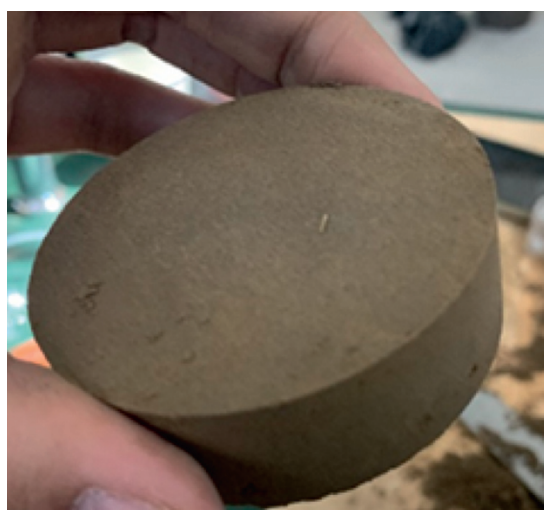

(a)

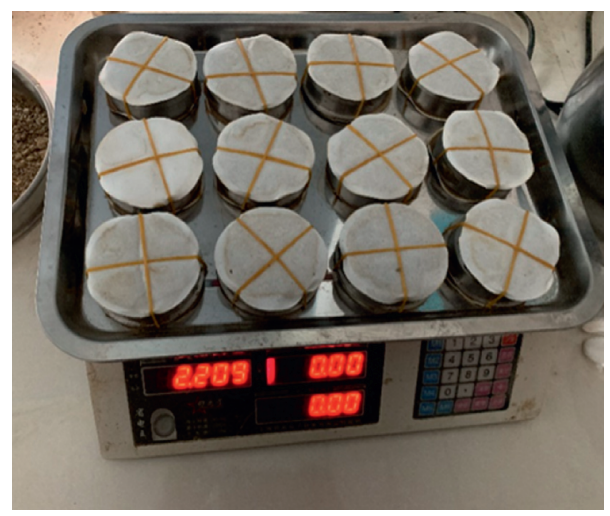

(b)

Figure 9: Part of the test process. (a) Soil sample prepared. (b) Weighing the test samples.

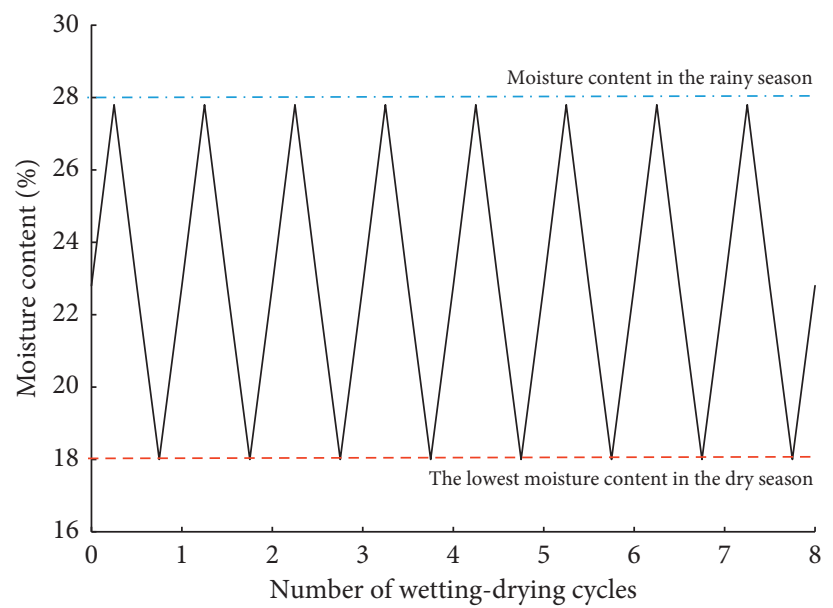

FIGURE 10: The moisture content change path of the wetting-drying cycles used in this test.

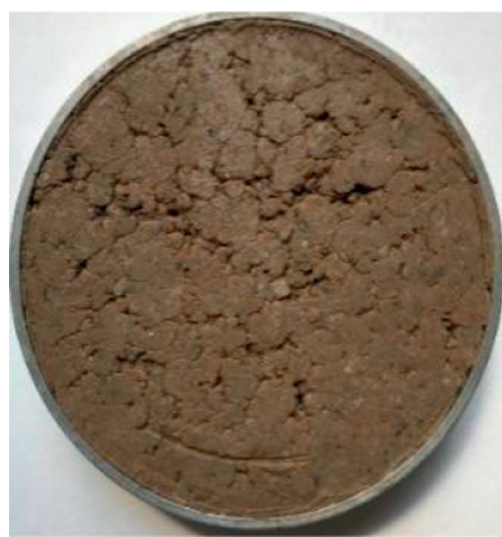

(a)

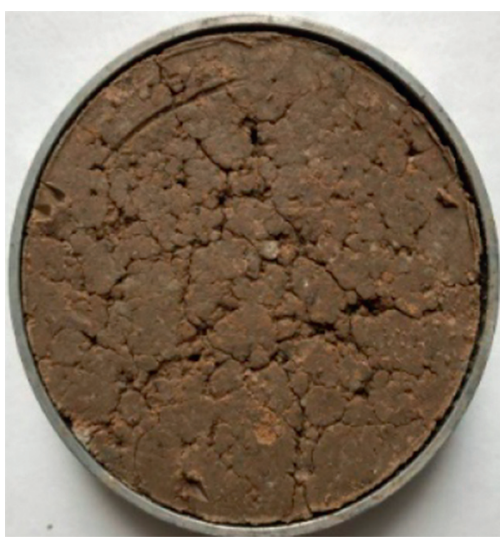

(b)

Figure 11: Continued. 


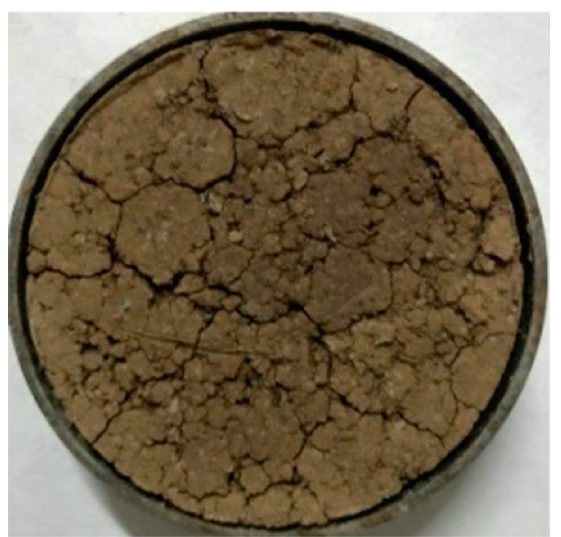

(c)

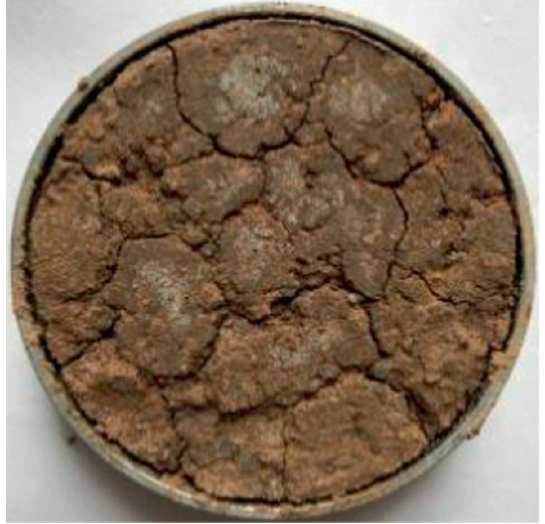

(d)

Figure 11: Fissure development under different wetting-drying cycles: (a) 2 times, (b) 4 times, (c) 6 times, and (d) 8 times.

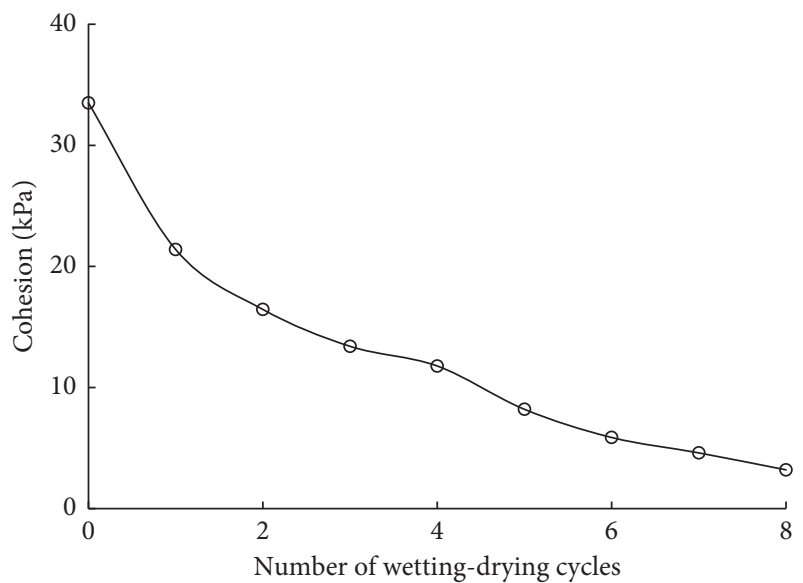

FIGURE 12: Relationship between cohesion and the number of wetting-drying cycles.

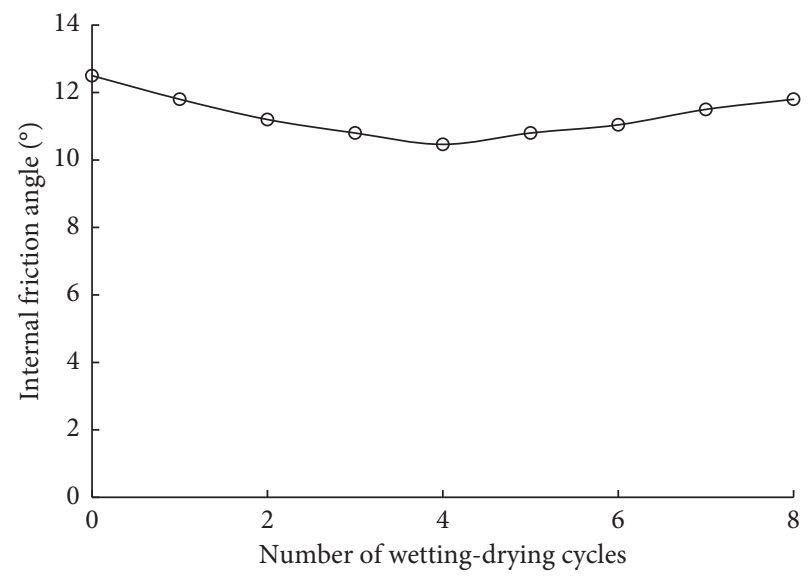

FIGURE 13: Relationship between internal friction angle and the number of wetting-drying cycles.

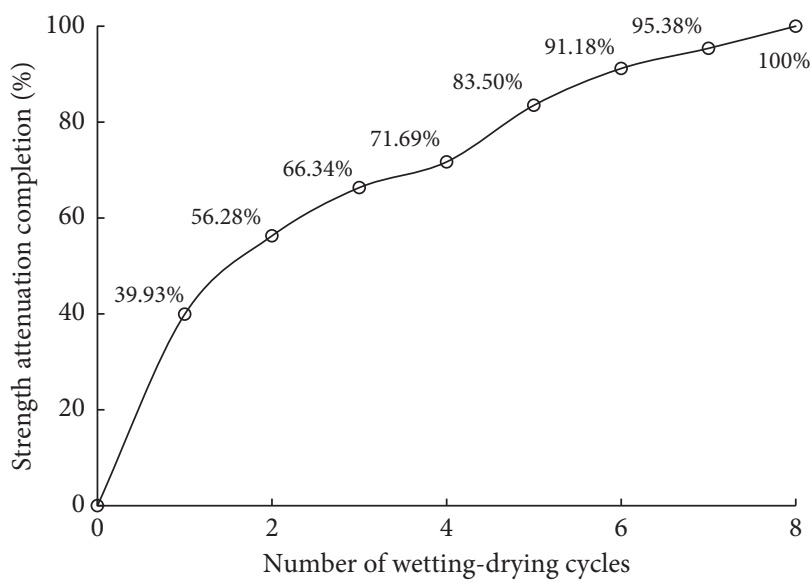

FIGURE 14: Relationship between the completion degree of intensity attenuation and the number of wetting-drying cycles.

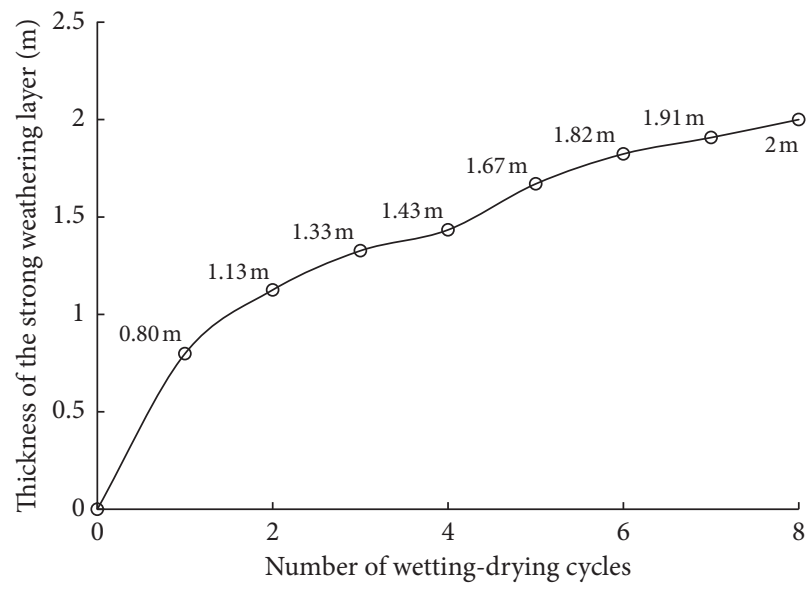

FIGURE 15: Relationship between the thickness of the severe weathered layer and the number of wetting-drying cycles. 


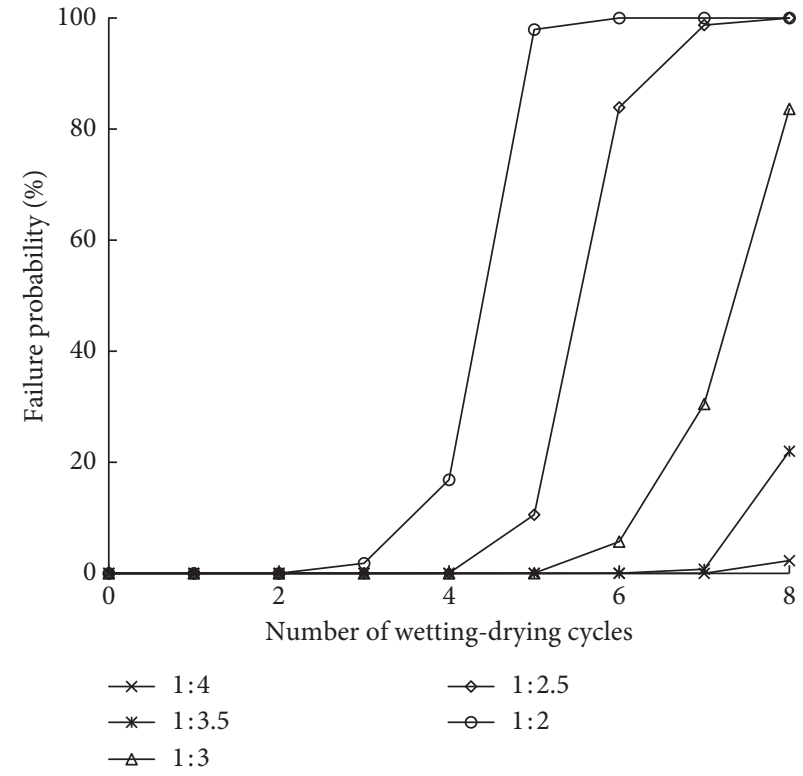

(a)

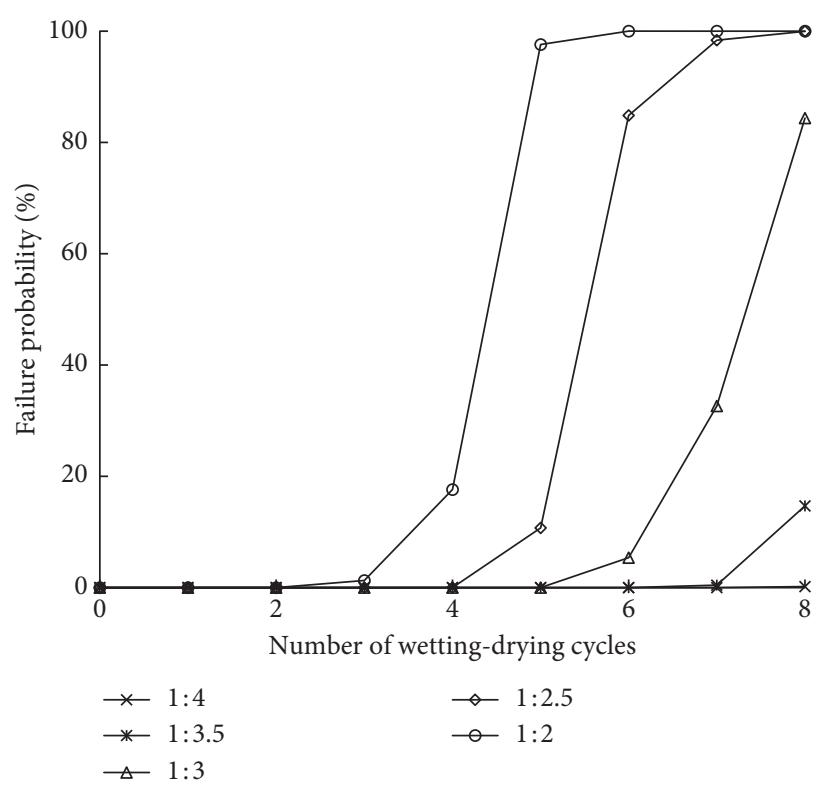

(b)

Figure 16: Relationship between the thickness of the severe weathered layer and the number of wetting-drying cycles. (a) Normal distribution. (b) Lognormal distribution.

probability of failure increases significantly is advanced after 4 or 5 wetting-drying cycles. It shows that cutting the slope would help alleviate the adverse effects of wetting-drying cycles. The trends for different distribution types are consistent.

4.2. Sensitivity Analysis of Parameter Variability. To better analyze the effect of soil parameters on the stability of the expansive soil slope located in Nanjing, Jiangsu Province, China, the sensitivity of random variables is analyzed. Assuming that the coefficient of the random variables ranges from 0.1 to 0.6 , the values of the basic parameters of the soil are shown in Table 2. The engineering parameters are identical to those presented in Figure 2 for a slope ratio of $1: 4$.

According to different coefficients of variation, the reliability of slope stability is analyzed with the whole rigid body equilibrium method. The results of a sensitivity analysis for a normal or lognormal distribution of $c$ and $\varphi$ are shown in Figure 17.

As can be seen from Figure 17, the reliability index shows a continuous decrease with an increase in the coefficient of variation $(c$ or $\varphi)$, which indicates that the probability of failure increases with an increase in the coefficient of variation parameter. The sensitivity of the parameters is less likely to be affected by the type of distribution. The decreasing trend of the reliability index is similar for different types of distribution, i.e., faster at the beginning and weaker at a later stage. The rate of decline of parameter $c$ is lower than that of parameter $\varphi$. Additionally, the curve of the decline of the reliability index of the former is nearly linear, while that of the latter is faster at the early stages but slower at the later stages. It is apparent from the figure that the reliability index for the logarithmic distribution is higher than that for the normal distribution when the coefficient of variation is small. Hence, the normal distribution can be adopted in the calculation process since it entails a relatively "safer" calculation.

\section{Discussion}

5.1. Reliability Analysis of the Slope Based on the Monte Carlo Method. To verify the accuracy of the reliability index calculated by the method in this paper, the Monte Carlo method was used to analyze the stability of the expansive soil slope for different numbers of wetting-drying cycles. The values of the slope parameters are consistent with those in Section 4.1. The calculated probability of failure varies with the number of wetting-drying cycles, as shown in Figure 18.

As shown in Figure 18, the trend of the probability of failure is similar to that calculated by the method proposed in this paper in Figure 16, and the error is within 5\%, indicating that the method proposed in this article is reasonable. Therefore, this method can be further applied to other cases.

5.2. Case Studies. To verify the accuracy of the reliability index calculated by the procedure with the whole rigid body equilibrium method in the spreadsheet, the values of soil parameters and other parameters from five typical expansive soil slope cases were obtained from the literature $[7,11,12,34,35]$ in this paper. The computed results are listed in Table 4 and compared to the original values.

According to the results, the reliability obtained with the proposed method better reflects the stability of expansive soil slopes. From the point of view of probability, the 


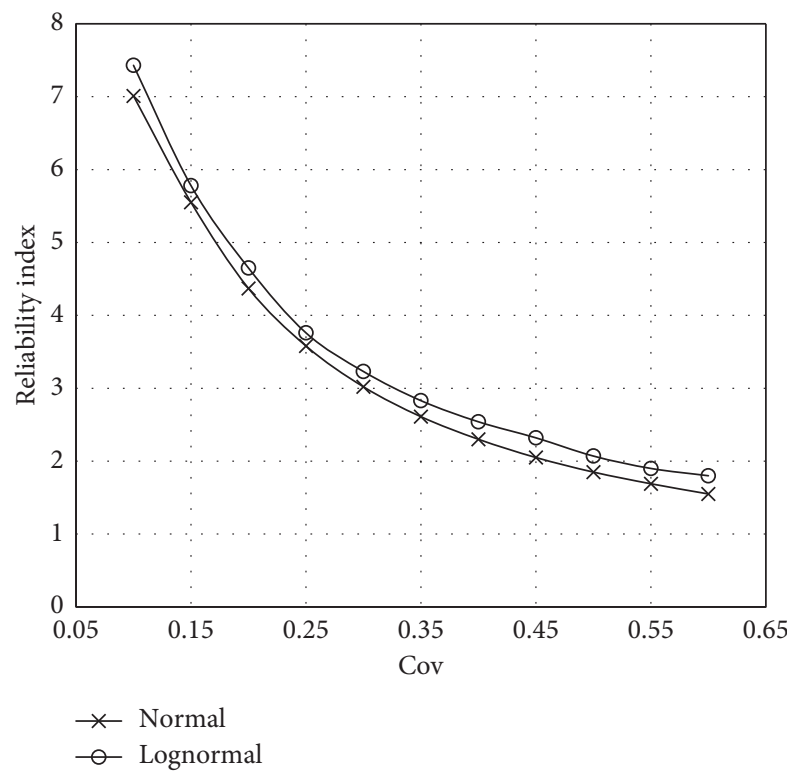

(a)

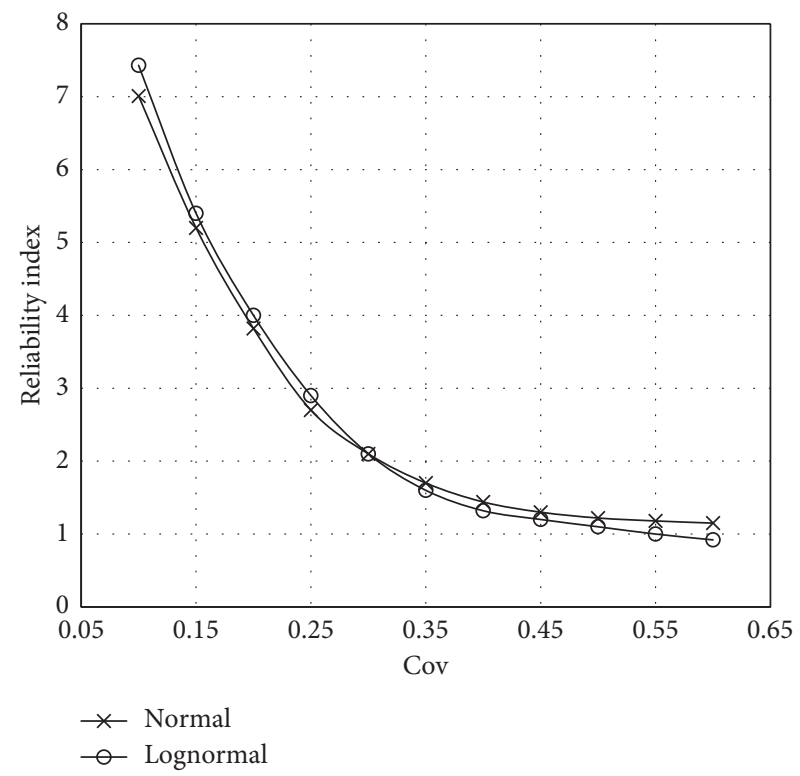

(b)

Figure 17: The results of sensitivity analysis of (a) parameter $c$ and (b) parameter $\varphi$.

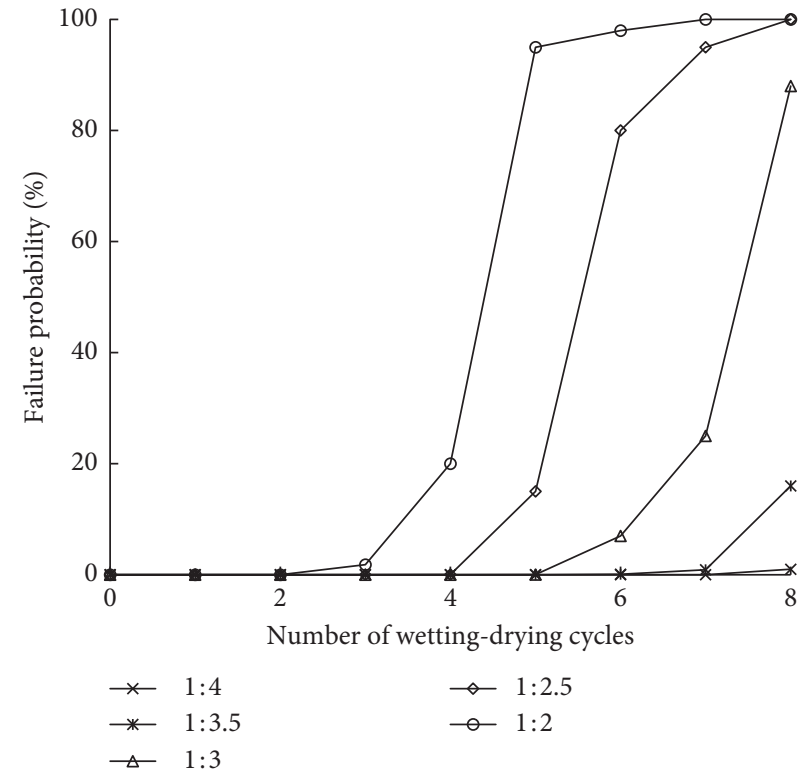

(a)

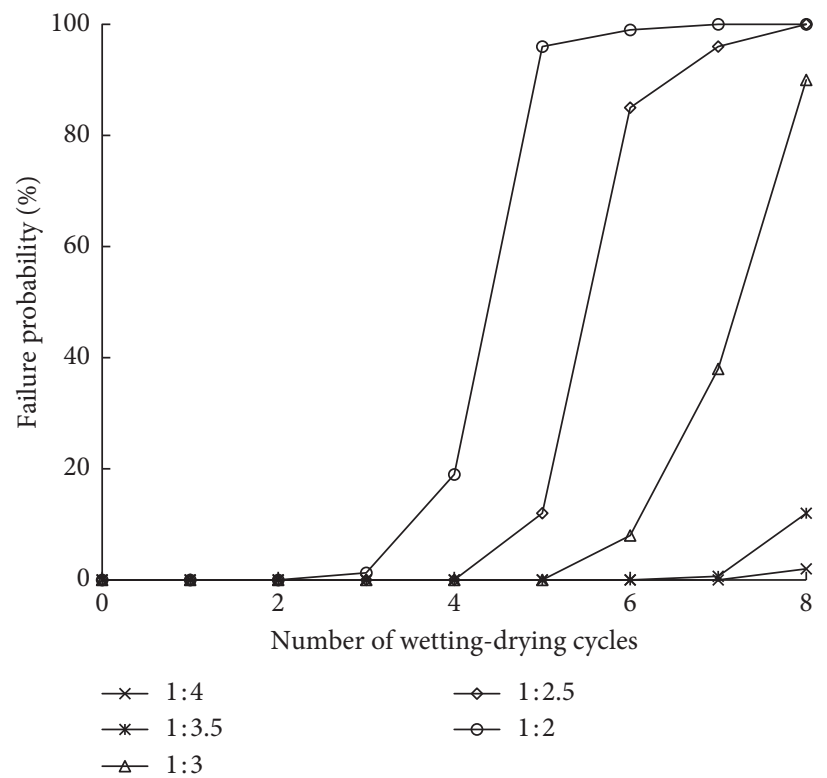

(b)

Figure 18: Relationship between the thickness of the severe weathered layer and the number of wetting-drying cycles. (a) Normal distribution. (b) Lognormal distribution.

reliability index can better reflect the effects of soil variability on slope stability. Even if the FS in the original paper is calculated with deterministic methods or numerical analysis and meets the required specifications, the reliability index may not meet the requirement of more than 3 . For example, in case 3 , the coefficient of variation of parameters is 0.3 , and the reliability index is 1.52 for the lognormal distribution and 1.35 for the normal distribution, indicating that the probability of failure increases to $6.42 \%$ (for the lognormal distribution) or $8.85 \%$ (for the normal distribution). In this 
TABLE 4: Results computed of five expansive soil slopes.

\begin{tabular}{|c|c|c|c|c|c|c|c|c|}
\hline \multirow{3}{*}{ Case } & \multicolumn{6}{|c|}{ Reliability index } & \multicolumn{2}{|r|}{ FS } \\
\hline & & Normal & & & Lognormal & & FS in this study & $F S$ in the origin \\
\hline & $\mathrm{Cov}=0.1$ & $\mathrm{Cov}=0.3$ & $\operatorname{Cov}=0.5$ & $\operatorname{Cov}=0.1$ & $\mathrm{Cov}=0.3$ & $\mathrm{Cov}=0.5$ & FS in this study & FS in the original paper \\
\hline 1 & 6.21 & 2.07 & 1.24 & 8.85 & 2.84 & 1.57 & 1.99 & 1.98 \\
\hline 2 & 0.52 & 0.17 & 0.1 & 0.46 & 0 & 0 & 1.04 & 1.1 \\
\hline 3 & 4.04 & 1.35 & 0.81 & 4.96 & 1.52 & 0.76 & 1.49 & 1.5 \\
\hline 4 & 1.6 & 0.53 & 0.32 & 1.69 & 0.43 & 0.11 & 1.17 & 1.29 \\
\hline 5 & 6.27 & 2.09 & 1.25 & 9.05 & 2.91 & 1.62 & 2.05 & 1.9 \\
\hline
\end{tabular}

manner, users are likely to better understand the stability of an expansive soil slope by combining the deterministic and the reliability-based methods.

\section{Conclusions}

Based on the engineering characteristics of the expansive soil and the characteristics of a dangerous sliding surface, this paper presents a novel simplified model combined with the reliability analysis method and draws the following conclusions:

(1) Based on the simplified model, the formulation to calculate the safety factors of the slope has been derived. Taking the slope of the Qinhuai Dong River as an example, very small deviations are observed between the results calculated with the whole rigid body equilibrium method and the FLAC strength reduction method. Besides, the disadvantageous effects of fissures on the overall force of the slip mass are considered in the method proposed in this paper.

(2) Combined with VBA and the built-in functions in a spreadsheet, a new spreadsheet method based on the RSM, which abandons the use of the "SOLVER" routine, has been proposed for calculating reliability using the safety factor calculation formulation for the integral rigid body equilibrium method. Considering the change in the strength of shallow soil and the depth of strong weathering, the relationships of the safety factor of the sliding surface at the interface between the strong and weak weathering layers for different stages of a wetting-drying cycle were analyzed. It was found that the probability of failure significantly increases after 4 or 5 wetting-drying cycles when the slope ratio is higher and that slope cutting helps alleviate the adverse effects of wettingdrying cycles.

\section{Data Availability}

The codes generated or used during the study are available from the corresponding author upon request. The data of soil parameters used in the numerical simulation are from the topic of "Instability Mechanism and Stability Measures of Expansive Soil Slope in Qinhuai Donghe Project" and may only be provided with restrictions.

\section{Conflicts of Interest}

The authors declare that they have no conflicts of interest regarding the publication of this paper.

\section{Acknowledgments}

The authors would like to acknowledge the financial support fromNational Key Research and Development Project (no. 2018YFC1508504), Special Funds for Basic Scientific Research Business in Central Universities (2016B43014), and the National Natural Science Foundation of China (no. 51778211).

\section{References}

[1] C. C. Ikeagwuani and D. C. Nwonu, "Emerging trends in expansive soil stabilisation: a review," Journal of Rock Mechanics and Geotechnical Engineering, vol. 11, no. 2, pp. 423-440, 2019.

[2] H. Ye, C. Chu, L. Xu, K. Guo, and D. Li, "Experimental studies on drying-wetting cycle characteristics of expansive soils improved by industrial wastes," Advances in Civil Engineering, vol. 2018, Article ID 2321361, 9 pages, 2018.

[3] N. S. Surjandari, N. Djarwanti, and N. U. Ukoi, "Enhancing the engineering properties of expansive soil using bagasse ash," Journal of Physics Conference Series, vol. 909, Article ID 012068, 2017.

[4] A. Soltani, A. Deng, and A. Taheri, "Swell-compression characteristics of a fiber-reinforced expansive soil," Geotextiles and Geomembranes, vol. 46, no. 2, pp. 183-189, 2018.

[5] S. Qi and S. K. Vanapalli, "Hydro-mechanical coupling effect on surficial layer stability of unsaturated expansive soil slopes," Computers and Geotechnics, vol. 70, pp. 68-82, 2015.

[6] Y. L. Zhu and G. P. Qi, "Linkages between precipitation cycle and slope stability: a case study in the Caijiapo land slide among Weihe River Basin," Conference Series: Earth \& Environmental Science, vol. 82, no. 1, Article ID 012092, 2017.

[7] L. Z. Wu, A. P. S. Selvadurai, L. M. Zhang, R. Q. Huang, and J. Huang, "Poro-mechanical coupling influences on potential for rainfall-induced shallow landslides in unsaturated soils," Advances in Water Resources, vol. 98, pp. 114-121, 2016.

[8] I. Noorany and C. Scheyhing, "Lateral extension of compacted-fill slopes in expansive soils," Journal of Geotechnical and Geoenvironmental Engineering, vol. 141, no. 1, Article ID 04014083, 2015.

[9] J. Wang, T. F. Gu, and Y. J. Xu, "Field tests of expansive soil embankment slope deformation under the effect of the rainfall 
evaporation cycle," Applied Ecology and Environmental Research, vol. 15, no. 3, pp. 343-357, 2017.

[10] C. Xie, Q. Shen, Z. Wu et al., "Stability analysis for the expansive soil slope considering the influence of cracks based on the upper bound method," IOP Conference Series: Earth and Environmental Science, vol. 189, Article ID 022014, 2018.

[11] Z. Jian, H. Peng, X. Jie et al., "Risk assessment model of expansive soil slope stability based on Fuzzy-AHP method and its engineering application," Geomatics Natural Hazards, vol. 9, no. 1, pp. 389-402, 2018.

[12] S. Qi and S. K. Vanapalli, "Influence of swelling behavior on the stability of an infinite unsaturated expansive soil slope," Computers and Geotechnics, vol. 76, pp. 154-169, 2016.

[13] S. Y. Wen, J. L. Li, X. T. Yang et al., "Multistage fuzzy comprehensive evaluation for analyzing unloading high-steep slope stability," Rock and Soil Mechanic, vol. 27, no. 11, pp. 2041-2044, 2006.

[14] H. Peng, S. C. Li, X. Jie et al., "Shallow sliding failure prediction model of expansive soil slope based on Gaussian process theory and its engineering application," KSCE Journal of Civil Engineering, vol. 5, pp. 1-11, 2017.

[15] D. Q. Li, T. Xiao, Z. J. Cao, K.-K. Phoon, and C. B. Zhou, "Efficient and consistent reliability analysis of soil slope stability using both limit equilibrium analysis and finite element analysis," Applied Mathematical Modelling, vol. 40, no. 9-10, pp. 5216-5229, 2016.

[16] Z. Cao, W. Yu, and D. Li, "Practical reliability analysis of slope stability by advanced Monte Carlo simulations in a spreadsheet," Canadian Geotechnical Journal, vol. 48, no. 1, pp. 162-172, 2011.

[17] J. Zhang, L. M. Zhang, and W. H. Tang, "New methods for system reliability analysis of soil slopes," Canadian Geotechnical Journal, vol. 48, no. 7, pp. 1138-1148, 2011.

[18] A. Johari and A. Gholampour, "A practical approach for reliability analysis of unsaturated slope by conditional random finite element method," Computers and Geotechnics, vol. 102, pp. 79-91, 2018.

[19] T. L. Chen, C. Zhou, G. L. Wang et al., "Centrifuge model test on unsaturated expansive soil slopes with cyclic wettingdrying and inundation at the slope toe," International Journal of Civil Engineering, vol. 16, no. 6, pp. 1-20, 2017.

[20] L. Liao and S. Liu, "The engineering characteristics of expansive soil and its engineering measures," Water Conservancy and Hydropower Science and Technology Development, vol. 21, no. 2, pp. 37-40, 2001.

[21] B. Shi, H. Jiang, Z. Liu, and H. Y. Fang, "Engineering geological characteristics of expansive soils in China," Engineering Geology, vol. 67, no. 1-2, pp. 63-71, 2002.

[22] Z. Z. Yin and X. .U. Bin, "Slope stability of expansive soil under fissure influence," Chinese Journal of Geotechnical Engineering, vol. 33, no. 3, p. 454, 2011.

[23] A. Mahdiyar, M. Hasanipanah, D. J. Armaghani et al., "A Monte Carlo technique in safety assessment of slope under seismic condition," Engineering with Computers, vol. 33, no. 4, pp. 1-11, 2017.

[24] A. Johari and H. Rahmati, "System reliability analysis of slopes based on the method of slices using sequential compounding method," Computers and Geotechnics, vol. 114, pp. 103-116, 2019.

[25] D.-Q. Li, F.-P. Zhang, Z.-J. Cao, W. Zhou, K.-K. Phoon, and C.-B. Zhou, "Efficient reliability updating of slope stability by reweighting failure samples generated by Monte Carlo simulation," Computers and Geotechnics, vol. 69, pp. 588-600, 2015.
[26] B. K. Low, "Reliability-based design applied to retaining walls," Géotechnique, vol. 55, no. 1, pp. 63-75, 2005.

[27] B. K. Low and K.-K. Phoon, "Reliability-based design and its complementary role to Eurocode 7 design approach," Computers and Geotechnics, vol. 65, pp. 30-44, 2015.

[28] B. K. Low, J. Zhang, and W. H. Tang, "Efficient system reliability analysis illustrated for a retaining wall and a soil slope," Computers and Geotechnics, vol. 38, no. 2, pp. 196-204, 2011.

[29] J. Jian, C. Zhang, Y. Gui, Q. Lu et al., "New observations on the application of LS-SVM in slope system reliability analysis," Journal of Computing in Civil Engineering, vol. 31, no. 2, pp. 06016002.1-06016002.9, 2016.

[30] A. Johari, A. Sabzi, and A. Gholaminejad, "Reliability analysis of differential settlement of strip footings by stochastic response surface method," Iranian Journal of Science and Technology-Transactions of Civil Engineering, vol. 43, no. 5, pp. 1-12, 2018.

[31] S. H. Huang and J. S. Huang, "Efficient slope reliability analysis at low-probability levels in spatially variable soils," Computers and Geotechnics, vol. 75, pp. 18-27, 2016.

[32] D.-Q. Li, D. Zheng, Z.-J. Cao, X.-S. Tang, and K.-K. Phoon, "Response surface methods for slope reliability analysis: review and comparison," Engineering Geology, vol. 203, pp. 314, 2016.

[33] K. K. Phoon, "Reliability-based design in geotechnical engineering: computations and applications," Structure Infrastructure Engineering, vol. 7, no. 3, pp. 259-260, 2011.

[34] H. Yao, S. Zheng, W. Li et al., "Parametric study on the effect of rain infiltration on stability of unsaturated expansive soil slope," Chinese Journal of Rock Mechanics, vol. 21, no. 7, pp. 1034-1039, 2002.

[35] H. Sun, B. Hu, and G. Q. Zhang, "Analysis of fissured expansive soil slope stability and its reinforcement with antislippery piles," Applied Mechanics \& Materials, vol. 275-277, pp. 1489-1492, 2013. 